\title{
The effect of step stool use and provider height on CPR quality during pediatric cardiac arrest: A simulation-based multicentre study
}

\author{
Adam Cheng, MD*; Yiqun Lin, MD, MHSc*; Vinay Nadkarni, $\mathrm{MD}^{\dagger}$; Brandi Wan, BKin*; Jonathan Duff, \\ $\mathrm{MD}^{\ddagger}$; Linda Brown, MD, MSCE ${ }^{\S}$; Farhan Bhanji, MD, MSc (Ed) ${ }^{\text {ศT; }}$ David Kessler, MD, MSc ${ }^{* *}$; \\ Nancy Tofil, MD, Med ${ }^{\dagger+}$; Kent Hecker, $\mathrm{PhD}^{\ddagger \ddagger \S \S}$; Elizabeth A. Hunt, MD, MPH, PhD ${ }^{\text {II; }}$; on behalf of the \\ International Network for Simulation-based Pediatric Innovation, Research and Education (INSPIRE) \\ CPR Investigators
}

\begin{abstract}
Objectives: We aimed to explore whether a) step stool use is associated with improved cardiopulmonary resuscitation (CPR) quality; b) provider adjusted height is associated with improved CPR quality; and if associations exist, c) determine whether just-in-time (JIT) CPR training and/or CPR visual feedback attenuates the effect of height and/or step stool use on CPR quality.

Methods: We analysed data from a trial of simulated cardiac arrests with three study arms: No intervention; CPR visual feedback; and JIT CPR training. Step stool use was voluntary. We explored the association between 1) step stool use and CPR quality, and 2) provider adjusted height and CPR quality. Adjusted height was defined as provider height $+23 \mathrm{~cm}$ (if step stool was used). Below-average height participants were $\leq$ gender-specific average height; the remainder were above average height. We assessed for interaction between study arm and both adjusted height and step stool use.
\end{abstract}

Results: One hundred twenty-four subjects participated; 1,230 30-second epochs of CPR were analysed. Step stool use was associated with improved compression depth in belowaverage (female, $p=0.007$; male, $p<0.001$ ) and aboveaverage (female, $p=0.001$; male, $p<0.001$ ) height providers. There is an association between adjusted height and compression depth $(p<0.001)$. Visual feedback attenuated the effect of height $(p=0.025)$ on compression depth; JIT training did not $(p=0.918)$. Visual feedback and JIT training attenuated the effect of step stool use $(p<0.001)$ on compression depth.
Conclusions: Step stool use is associated with improved compression depth regardless of height. Increased provider height is associated with improved compression depth, with visual feedback attenuating the effects of height and step stool use.

\section{RÉSUMÉ}

Objectifs: L'étude visait à déterminer : a) si l'utilisation d'un marchepied était associée à une amélioration de la qualité des manœuvres de réanimation cardiorespiratoire (RCR); b) si la hauteur rajustée des fournisseurs de soins était associée à une amélioration de la qualité des manœuvres de RCR; et s'il existait des relations entre ces éléments c) si la formation juste-à-temps sur la RCR ou la rétroaction visuelle sur la RCR atténuaient les effets de la hauteur ou de l'utilisation du marchepied sur la qualité de la RCR.

Méthode: Ont été analysées des données provenant d'un essai d'arrêts cardiaques simulés, divisé en trois groupes : sans intervention, avec rétroaction visuelle sur la RCR et avec formation juste-à-temps sur la RCR. Les participants étaient libres d'utiliser ou non un marchepied. Les chercheurs ont tenté de déterminer s'il existait une relation entre 1) I'utilisation du marchepied et la qualité des manœuvres de RCR et 2) la hauteur rajustée des fournisseurs de soins et la qualité des manœuvres de RCR. La hauteur rajustée a été définie comme la taille du fournisseur de soins $+23 \mathrm{~cm}$ (en cas d'utilisation du marchepied). Les participants considérés comme petits avaient une taille égale ou inférieure à la moyenne de la taille liée au sexe; les autres étaient de taille

From the *KidSIM-ASPIRE Research Program, Department of Pediatrics, Alberta Children's Hospital, Calgary, AB; †Children's Hospital of Philadelphia, University of Pennsylvania Perelman School of Medicine, Philadelphia, PA; ¥Stollery Children's Hospital, University of Alberta, Edmonton, AB; $\S$ Hasbro Children's Hospital, Alpert Medical School of Brown University, Providence, Rl; đMontreal Children's Hospital, McGill University, Montreal, QC; **Columbia University College of Physicians and Surgeons, New York, NY; †tChildren's of Alabama, University of Alabama at Birmingham, Birmingham, AL; $¥ \neq D$ Department of Veterinary and Diagnostic Sciences and §§Department of Community Health Sciences, University of Calgary, Calgary, AB; and the १ףTCharlotte R. Bloomberg Children's Center, Division of Pediatric Anesthesiology and Critical Care Medicine, Johns Hopkins University School of Medicine, Baltimore, MD.

Correspondence to: Dr. Adam Cheng, Department of Pediatrics, Alberta Children's Hospital, 2888 Shaganappi Trail NW, Calgary, AB T3B 6A8; Email: chenger@me.com 
supérieure à la moyenne. Les auteurs se sont penchés sur l'existence d'une interaction entre les groupes à l'étude et tant la hauteur rajustée que l'utilisation du marchepied.

Résultats: Cent vingt-quatre sujets ont participé à l'étude, et 1230 périodes de RCR, d'une durée de 30 secondes, ont été analysées. L'utilisation du marchepied a été associée à une profondeur accrue des compressions thoraciques chez les fournisseurs de soins de taille inférieure (femmes : $p=0,007$; hommes : $p<0,001$ ) et de taille supérieure (femmes : $p=0,001$; hommes : $p<0,001$ ) à la moyenne. Il existe une relation entre la hauteur rajustée et la profondeur des compressions $(p<0,001)$. La rétroaction visuelle a atténué l'effet de la hauteur $(p=0,025)$ sur la profondeur des compressions, mais pas la formation juste-à-temps $(p=0,918)$. Par contre, la rétroaction visuelle et la formation juste-à-temps ont toutes deux atténué l'effet de l'utilisation du marchepied $(p<0,001)$ sur la profondeur des compressions. Conclusions: L'utilisation du marchepied a été associée à une profondeur accrue des compressions, indépendamment de la taille. Le fait de hausser la position des fournisseurs de soins a été associé à une profondeur accrue des compressions, mais la rétroaction visuelle a atténué les effets de la hauteur et de l'utilisation du marchepied.

Keywords: cardiac arrest, cardiopulmonary resuscitation, chest compressions, height, pediatric, step stool

\section{INTRODUCTION}

The provision of guideline-compliant cardiopulmonary resuscitation (CPR) improves patient outcomes for inand out-of-hospital cardiopulmonary arrest (CPA). ${ }^{1-7}$ Unfortunately, even trained providers struggle to perform guideline-compliant CPR during simulated and real CPA events. ${ }^{8-17}$ Provider characteristics and step stool use may influence the quality of CPR.

Prior studies report mixed results when describing the association between rescuer height and the delivery of adequate CPR. ${ }^{18,19}$ Step stool use improves chest compression (CC) depth provided to adult-sized manikins ${ }^{20}$ with a more pronounced effect in shorter rescuers. ${ }^{21}$ The impact of provider height and step stool use has not been quantified for pediatric CPR. Many institutions have implemented just-in-time (JIT) CPR training $^{15,22}$ conducted directly prior to a CPA event, and the use of real-time visual feedback ${ }^{15,23,24}$ during CPR to help improve CPR quality. ${ }^{25}$ It is unknown whether these interventions modify the effect of height and step stool use on CPR quality.

In our study, we describe the influence of step stool use and height on the quality of CPR provided during a simulated pediatric CPA, with and without the use of realtime CPR feedback and prior JIT CPR training. The primary objective of this study is to explore whether step stool use is associated with improvement in CPR quality in providers of below- or above-average height. Our secondary objectives are to a) explore whether adjusted height (defined as the height of the CPR provider + $23 \mathrm{~cm}$ if a step stool was used) is associated with improvement in CC depth and rate; and if there is an association, b) determine whether visual feedback or JIT CPR training attenuates the effect of height on CC depth and rate and c) determine whether visual feedback or JIT CPR training attenuates the effect of step stool use on CC depth and rate.

\section{METHODS}

In this study, we conducted a secondary analysis of data collected from a prospective, randomized controlled, multicentre trial assessing the impact of real-time visual feedback during simulated CPA and JIT CPR training with visual feedback before simulated $\mathrm{CPA}$ on the quality of CPR. ${ }^{15}$ Participants were consented prior to participation in the study, and an ethics board approval was obtained at all sites.

\section{Study participants}

Participants were recruited from 10 children's hospitals (3 Canadian sites, $1 \mathrm{UK}$ site, 6 sites in the United States) into teams of three, with pre-assigned roles of CPR provider (two participants) and event leader (one participant). ${ }^{15}$ Participants were recruited between July 1, 2012 and April 15, 2014. Participants were eligible to be recruited as CPR providers if they were pediatric health care providers (nurses, medical students, residents, attending pediatricians) with recent (i.e., past 2 years) certification in basic life support (BLS), advanced cardiac life support (ACLS), and/or pediatric advanced life support (PALS). Participants served as event leaders if they were general pediatric attending physicians, fellows in pediatric emergency medicine, anesthesia, or critical care and residents (years two through four) in anesthesia, emergency medicine, family medicine, or pediatrics with recent certification in ACLS and/or PALS. Exclusion criteria included subjects with prior 
experience using a CPR feedback device during real or simulated CPA. ${ }^{15}$

\section{Outcome measures}

To be consistent with prior CPR studies, ${ }^{11,12}$ we used 30-second epochs of CPR as the unit of measure. CPR quality data were collected from the manikin (SimJunior, Laerdal Corporation), with mean CC depth and CC rate averaged over each 30-second epoch of resuscitation. Our primary outcome was mean CC depth, and our secondary outcome was mean CC rate.

\section{Study procedures}

\section{Site inclusion}

We collected data from participants in arms 1 (no intervention), 2 (real-time visual feedback during CPA) and 3 (JIT CPR training prior to CPA) of the main study. ${ }^{15}$ Randomization occurred at the level of the team, was stratified by study site, and conducted in blocks. ${ }^{15}$ A secondary analysis of data was conducted from all 10 recruitment sites.

\section{Interventions for primary objective}

Step stool height $(23 \mathrm{~cm})$ and stretcher height $(71 \mathrm{~cm})$ were standardized. Step stool was voluntary and left up to the participant.

\section{Interventions for secondary objective}

We used the CPRCard (Laerdal Corporation) to provide real-time visual $\mathrm{CPR}$ feedback during the CPA scenario (arm 2). ${ }^{15}$ The device was calibrated to 2010 American Heart Association (AHA) guidelines for CPR quality, ${ }^{1}$ to provide corrective feedback via flashing lights for CC depth (set at depths of $<40 \mathrm{~mm}$, $40-50 \mathrm{~mm}$ for infant, $50-70 \mathrm{~mm}$ for child/adult on hard surface, and $>70 \mathrm{~mm}$ for child/adult on soft surface) and rate (set at rates of $<100,100-120$ and $>120$ compressions/minute). JIT CPR training (arm 3) was structured as a single practice session involving a 5-minute $\mathrm{CPR}$ training video and 2 minutes of CPR practice with visual feedback (CPRCard). CPR providers practiced while event leaders observed. Participants in the realtime visual feedback group (arm 2) did not watch a training video but did practice CPR for 2 minutes without visual feedback.
Standardized simulated scenarios, confederate actors, and the simulation environment

Participant height and gender were collected upon recruitment. Each CPR provider completed 2 minutes of CPR practice (with or without JIT training). All teams then completed a 15 -minute pediatric septic shock scenario followed by a short debriefing (with no discussion of CPR). A 12-minute pediatric CPA simulation was run for all teams, during which CPR quality data were collected for analysis. ${ }^{15}$

We standardized our research methodology across all sites to minimize the effect of simulation-specific confounding variables. ${ }^{26}$ The CPA scenario was preprogrammed, and all research facilitators used a scenario script to ensure consistency in scenario execution. The clinical environment across all sites was standardized (i.e., identical equipment availability and location), and actors playing the roles of respiratory therapist and medication nurse were trained in an identical fashion. One bird's eye view camera angle from the foot of the bed was captured for video review. All sites used the same pediatric simulator, SimJunior, specifically designed for CPR training. The simulator was placed on a hard stretcher to eliminate mattress compressibility as a potential confounder. ${ }^{27}$ The lights on the CPRCard were covered by black tape for the no-intervention arm and the JIT CPR training arm. To ensure compliance with study methodology, we reviewed all study videotapes during the study. One trained investigator reviewed all videos to assign each 30-second epoch of $\mathrm{CPR}$ to one provider and to document step stool use.

\section{Sample size}

Participants from the main study were used as a convenience sample for this study. ${ }^{15}$ All participants in arms 1, 2, and 3 were eligible for inclusion. Teams were excluded if video was not captured or if CPR data were missing. A maximum of 24 (30-second) epochs were analysed per simulated CPA event, and 30-second epochs of CPR where two participants provided CPR were identified via video review and subsequently excluded from analysis.

\section{Statistical analysis}

All data analyses were performed using $\mathrm{R}$ version 3.2.1 (available at www.r-project.org). Demographic information was summarized with number and percentage for 
categorical variables, and mean and standard deviation for numeric variables was given the normal distribution of CPR quality data. To evaluate the association between step stool use and the height of CPR providers, we categorized the participants into below-average versus above-average height groups using gender-specific cutoff points representing the average male and female heights in Canada (male $175.1 \mathrm{~cm}$, female $162.3 \mathrm{~cm}$ ). ${ }^{28}$ Participants falling at or below the gender-specific average height were considered below average height, whereas the remainder were considered above-average height. A $p$-value of less than 0.05 was considered statistically significant. Independent t-tests with Bonferroni correction were conducted to assess the difference between providers standing on the floor and step stool for both below- and above-average height groups for each gender in the entire cohort of participants. We define adjusted height as the height of the CPR provider $+23 \mathrm{~cm}$ if a step stool was used. Pearson correlation was used to assess the association between CC depth, CC rate, and adjusted height in the entire cohort and across all three groups. Multivariate linear regression was used to assess the a) interaction between group allocation and adjusted height, and b) interaction between group allocation and use of the step stool on CC depth and rate.

\section{RESULTS}

\section{Study population}

A total of 81 sessions (162 participants) were eligible for inclusion; 14 sessions were excluded due to missing data, and an additional 5 sessions were excluded due to a missing video. There was no clinically significant difference in CPR quality when comparing included sessions to those excluded due to a missing video. A total of 62 sessions (124 participants) were included in the analysis. The demographic characteristics of CPR providers are reported in Table 1. A total of 1,512 30 -second epochs were available for analysis. Excluding 30 -second epochs contributed by two CPR providers (282 epochs), we included 1,230 epochs in the final analysis (Figure 1). The effects of JIT CPR training and real-time visual feedback on $\mathrm{CC}$ quality are reported elsewhere. $^{15}$

\section{Effect of step stool use on chest compression depth and rate}

A step stool was used in 242 epochs $(72.9 \%)$ in the below-average height group (females: 171 epochs [72.8\%]; males: 71 epochs [76.3\%]), and in 472 epochs $(52.6 \%)$ in the above-average height group (females:

\begin{tabular}{|c|c|c|c|c|c|}
\hline Characteristics & Group & Entire group & No intervention & Visual feedback & JIT training \\
\hline Gender & Female & $89(71.8)$ & $30(75.0)$ & $30(68.2)$ & $29(71.5)$ \\
\hline number (\%) & Male & $35(28.2)$ & $10(25.0)$ & $14(31.8)$ & $11(27.5)$ \\
\hline Occupation & Nurse & $61(49.1)$ & $17(42.5)$ & $22(50.0)$ & $22(55.0)$ \\
\hline \multirow[t]{3}{*}{ number (\%) } & Attending pediatrician & $2(1.6)$ & $1(2.5)$ & $1(2.5)$ & $0(0)$ \\
\hline & Medical student & $18(14.5)$ & $6(15.0)$ & $8(18.2)$ & $4(10.0)$ \\
\hline & Resident & $43(34.7)$ & $16(40.0)$ & $13(29.5)$ & $14(35.0)$ \\
\hline Last BLS/ACLS/PALS course taken & $<6$ months & $56(45.1)$ & $14(35.0)$ & $23(52.3)$ & 19 (47.65) \\
\hline \multirow[t]{2}{*}{ number (\%) } & 6-12 months & $42(33.9)$ & $16(40.0)$ & $12(27.3)$ & $14(35.0)$ \\
\hline & $>12$ months & $26(21.0)$ & $10(25.0)$ & $9(20.5)$ & 7 (17.5) \\
\hline $\begin{array}{l}\text { CPR done on simulator or real } \\
\text { patients in the past } 2 \text { years }\end{array}$ & $1-5$ times & $93(75.0)$ & 31 (77.5) & $32(72.7)$ & $30(75.0)$ \\
\hline \multirow[t]{3}{*}{ number (\%) } & $>5$ times & $9(7.3)$ & $2(5.0)$ & $4(9.1)$ & $3(7.5)$ \\
\hline & Never & $22(17.7)$ & 7 (17.5) & $8(18.2)$ & 7 (17.5) \\
\hline & Mean (SD) mm & $169.7(9.7)$ & $169.1(10.3)$ & $171.1(9.8)$ & $168.9(9.1)$ \\
\hline Height* & Below average & $34(27.4)$ & $11(27.5)$ & 12 (27.3) & $11(27.5)$ \\
\hline \multirow[t]{2}{*}{ number (\%) } & Above average & $90(72.6)$ & $29(71.5)$ & $32(72.7)$ & 29 (71.5) \\
\hline & Total & 124 & 40 & 44 & 40 \\
\hline
\end{tabular}




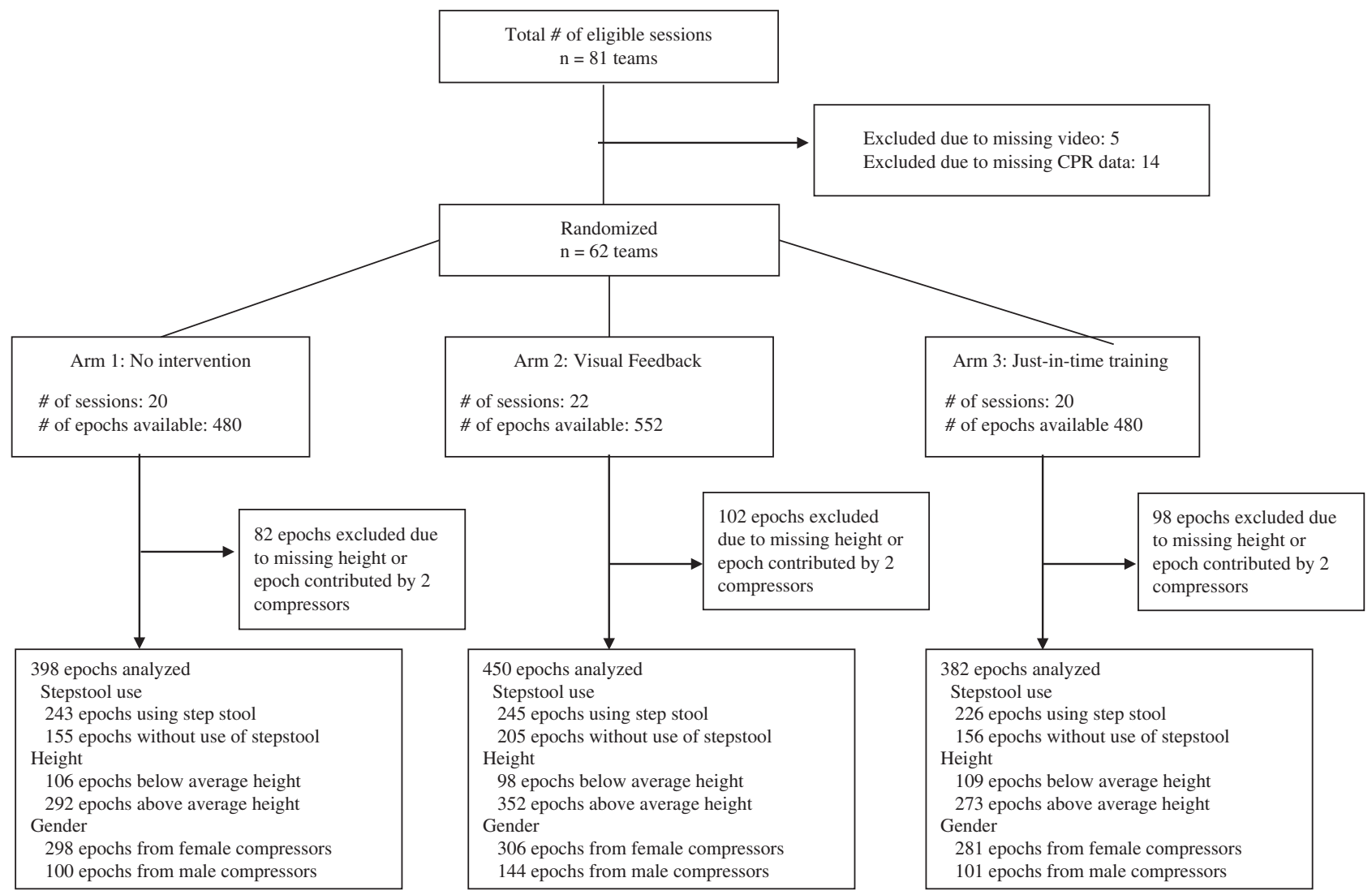

Figure 1. Study flow diagram.

417 epochs [64.7\%]; males: 55 epochs [21.7\%]). The use of a step stool improves CC depth for providers of below-average height (females: $33 \pm 7.7 \mathrm{~mm}$ without step stool v. $36 \pm 6.6 \mathrm{~mm}$ with step stool, $p=0.007$; males: $30 \pm 1.8 \mathrm{~mm}$ without step stool v. $37 \pm 10.2 \mathrm{~mm}$ with step stool, $p<0.001)$. Use of a step stool also improves CC depth for providers of above-average height (females: $34 \pm 8.4 \mathrm{~mm}$ without step stool $\mathrm{v}$. $36 \pm 7.8 \mathrm{~mm}$ with step stool, $p=0.001$; males: $38 \pm 9.6 \mathrm{~mm}$ without step stool v. $41 \pm 3.6 \mathrm{~mm}$ with step stool, $p<0.001$ ) (Figure 2).

The use of a step stool improves CC rate for females of above-average height $(118 \pm 10 \mathrm{~mm}$ without step stool v. $121 \pm 13 \mathrm{~mm}$ with step stool, $p=0.001$ ) and for males of below-average height $(99 \pm 11 \mathrm{~mm}$ without step stool v. $121 \pm 21 \mathrm{~mm}$ with step stool, $p<0.001)$. There was no significant difference in $\mathrm{CC}$ rate for females of below-average height $(123 \pm 15 \mathrm{~mm}$ without step stool v. $121 \pm 15 \mathrm{~mm}$ with step stool, $p=0.40$ ) and for males of above-average height $(120 \pm 11 \mathrm{~mm}$ without step stool v. $121 \pm 13 \mathrm{~mm}$ with step stool, $p=0.37$ ). When adjusting for the study group, the effect of step

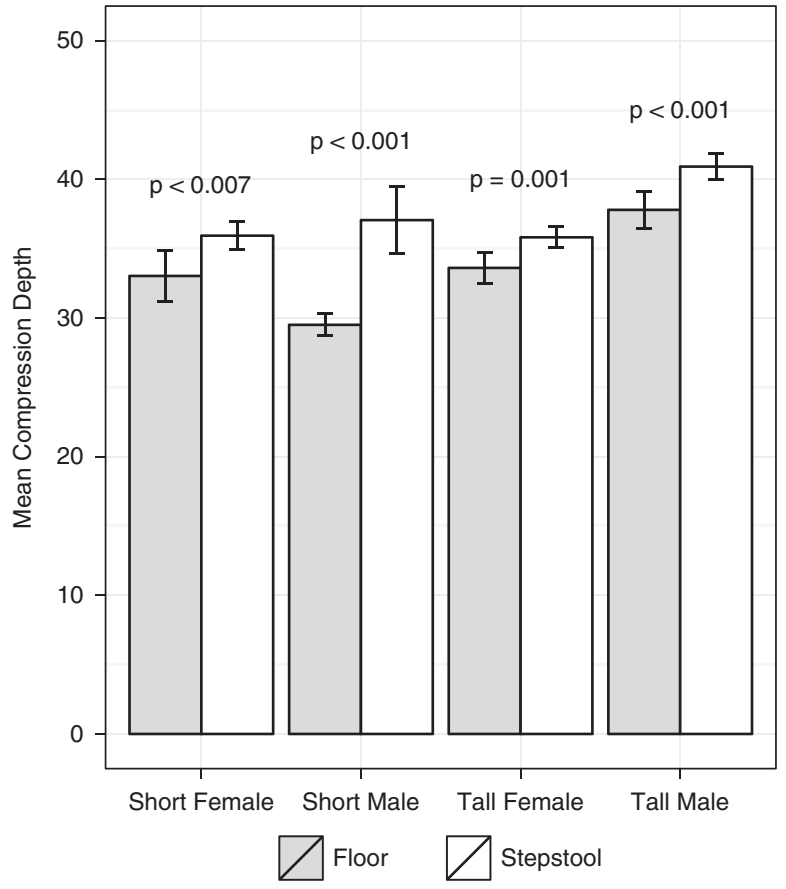

Figure 2. Effect of step stool use on mean chest compression depth in providers of below- and aboveaverage heights. 
stool use on compression depth and rate remains the same in both below- and above-average height groups.

\section{Correlation between adjusted height and chest compression depth and rate}

There is a statistically significant correlation between adjusted height and mean CC depth $(p<0.001)$. The correlation remained significant in the no-intervention group, JIT training group, and visual feedback group ( $p<0.001$ in all three groups). A $10-\mathrm{cm}$ increase in height is correlated with a $2-\mathrm{mm}$ increase in mean CC depth in both the no-intervention group $(p<0.001)$ and JIT training group $(p<0.001)$, and a $0.9-\mathrm{mm}$ increase in the visual feedback group $(p<0.001)$.

There is no association between adjusted height and mean CC rate $(p=0.715)$, even after adjusting for the study group $(p=0.55)$.

\section{Does just-in-time training or visual feedback attenuate the effect of height on chest compression depth?}

After adjusting for gender, the use of visual feedback was found to attenuate the effect of adjusted height on CC depth $(-1.1 \mathrm{~mm}$ per $10 \mathrm{~cm}$ increase in the adjusted height; $p=0.025)$. Prior JIT training was not found to attenuate the effect of the adjusted height on CC depth $(p=0.918)$.

\section{Does just-in-time training or visual feedback attenuate the effect of step stool use on chest compression depth?}

After adjusting for gender and provider height, the use of visual feedback was found to attenuate the effect of step stool use on CC depth $(-4.4 \mathrm{~mm}$ with real-time feedback; $p<0.001)$. Prior JIT training was also found to attenuate the effect of step stool use on CC depth (-6.6 mm with JIT training; $p<0.001)$.

\section{DISCUSSION}

Our study is the first to describe the influence of step stool use and height on the CC quality during pediatric CPA across multiple institutions. Increased provider adjusted height is associated with improved CC depth, and the use of visual feedback attenuates the effect of height and step stool use on CC depth. Prior JIT training attenuates the effect of step stool use on CC depth but was not found to attenuate the effect of adjusted height on CC depth. Importantly, use of a step stool is associated with improved CC depth.

Previous studies have assessed the impact of step stool use on CC depth using adult manikins in the context of CPR skills practice. Edelson et al. reported that use of a step stool resulted in an increased CC depth of $9 \mathrm{~mm}$ in shorter providers and $2 \mathrm{~mm}$ in taller providers, ${ }^{21}$ whereas Lee et al. described that step stool use in shorter providers resulted in improved CC depth compared with no step stool use. ${ }^{20}$ Our results are consistent with this prior work, ${ }^{20,21}$ demonstrating benefits of step stool use in pediatric CPR providers. Edelson et al. also describe an increase in the fraction of CC with incomplete recoil by an average of $18 \%$ across providers, ${ }^{21}$ thus bringing into question the relative benefit of step stool use. Given the larger reported increases in CC depth with step stool use in shorter providers in our study, we believe that the benefits of step stool use in this population are likely to outweigh the risks of poor recoil. ${ }^{21}$ These results enforce the importance of having a step stool available for use on resuscitation carts and in clinical areas where cardiac arrest is likely to occur. Furthermore, it is particularly important for all providers, regardless of height, to appreciate the importance of using a step stool and lowering the bed height when providing CC.

Deeper CCs are associated with improved survival and functional outcome from CPA. In a cohort of 89 pediatric in-hospital CPA patients, compliance with AHA recommendations for depth was associated with improved 24-hour survival. ${ }^{29}$ Vadeboncouer et al. demonstrated that each $5-\mathrm{mm}$ increase in mean CC depth during adult cardiac arrest increased the odds of survival by $29 \% .{ }^{30} \mathrm{~A}$ twofold increase in shock success is associated with a 5-mm increase in CC depth for both in and out-of-hospital cardiac arrests. ${ }^{31}$ KramerJohansen et al. demonstrated that each millimeter of increased CC depth during CPA was associated with a $5 \%$ increase in the odds of survival to hospital admission. ${ }^{32}$ Based on these studies, our findings that step stool use increases CC depth by $2-7 \mathrm{~mm}$ in a pediatricsized manikin represent statistically significant results that may be clinically relevant, depending on various factors (e.g., patient age, size, underlying condition). Given that the quality of CC during pediatric CPA is often substandard, ${ }^{10-12,15,16}$ we argue that step stools should be strongly considered for all CC providers. Further research is required to determine the relative benefit of increased CC depth when weighed against 
increased incomplete recoil for tall providers who use a step stool.

The influence of height on quality of pediatric CC has not been previously described. Studies using adult-sized manikins for CC skills have described mixed results when determining the association between provider height and CC depth. One study of 23 health care workers found positive association between provider height and CC depth. ${ }^{18}$ Medical students $<170 \mathrm{~cm}$ were unable to achieve CC depth $>40 \mathrm{~mm}$, whereas those taller than $170 \mathrm{~cm}$ were consistently above $40 \mathrm{~mm}$ in CC depth. ${ }^{20}$ Conversely, a different study found no differences in CC depth or rate between short and tall providers (with $170 \mathrm{~cm}$ as a cut-off). ${ }^{19}$ These studies measured performance over 2 minutes in a CPR skills-station, thus making it difficult to generalize the results to longer cardiac arrests in a clinical environment. To provide a more realistic context for assessment, we used a 12-minute simulated pediatric CPA. To accurately represent the influence of provider height on CC quality, we used adjusted height. Within resuscitation teams, the adjusted height of the CC provider should be optimized by ensuring step stool use and, when possible, selecting taller CC providers and/or those who have recently demonstrated competency in CC skills via JIT CPR training.

The use of real-time visual feedback during $\mathrm{CPA}^{7,12,15,24}$ and JIT CPR training ${ }^{13-15,22}$ prior to CPA are interventions that improve CPR quality. Both interventions are being integrated into clinical units in hospitals across North America. Our study is the first to describe that JIT training attenuates the effect of step stool use on CC depth. Furthermore, visual feedback attenuates the effect of both height and step stool use on CC depth. These findings can be attributed to the fact that both JIT training and visual feedback are strong interventions that improve CC quality, ${ }^{15}$ thus dampening the effect of other less impactful variables such as step stool use and height (in the case of visual feedback). Despite the attenuating effects of visual feedback on provider adjusted height, a weak correlation remains between adjusted height and CC depth. These results suggest that adjusted height should be considered regardless of whether visual feedback and JIT training are used.

\section{LIMITATIONS}

Our study has several limitations. Due to limitations in technology, we did not collect data for incomplete chest recoil. Future research could describe the impact of provider height on chest wall recoil in human patients. In this study, we did not measure or adjust for other quality of CPR metrics, namely pre-shock pause and CC fraction. We assessed that the performance of CPR using a single manikin simulator is unable to model the range of thoracic compliance that exists across the pediatric age spectrum. Further research is required to determine whether our results apply to pediatric patients of varying size and chest compliance. In our study, subjects elected to use a step stool at their own discretion, thus potentially introducing some selection bias to our results. We had more participants who were below average height, thus potentially introducing a sampling bias to our study. Although we had an uneven distribution of above- versus below-average height providers, our study represents the only study where the influence of height was assessed in the context of simulated or real resuscitation. As such, we believe that these data are a reasonable reflection of the influence of height and stool use on the quality of CC depth and rate across pediatric institutions.

\section{CONCLUSION}

Use of a step stool by CPR providers, regardless of gender and height, is associated with a statistically significant improvement in CC depth during simulated pediatric cardiac arrest. Increased provider height and step stool use improves compression depth, with visual feedback attenuating these effects. Future studies should explore the clinical impact of step stool use during real pediatric cardiac arrest.

Acknowledgements: The principal investigator (Adam Cheng) and Yiqun Lin had full access to all of the data in the study and take responsibility for the integrity of the data and the accuracy of the data analysis. Yiqun Lin (University of Calgary) conducted and is responsible for the data analysis. Clinical trial registration ID: NCT02075450; www.clinicaltrials.gov. INSPIRE Group Authors: Jennifer Davidson, RN, Alberta Children's Hospital, j_spruyt@ hotmail.com; Frank Overly, MD, Hasbro Children's Hospital, foverly@lifespan.org; Dawn Taylor Peterson, PhD, Children's of Alabama, dawn.taylorpeterson@childrensal.org; Marjorie Lee White, MD, MPPM, Med, Children's of Alabama, mlwhite@peds. uab.edu; John Zhong, MD, Children's Medical Center of Dallas, john.zhong@childrens.com; Vincent Grant, MD, Alberta Children's Hospital, vinceinfrance@gmail.com; David Grant, MBChB, MRCPCH, Bristol Royal Hospital for Children, david. grant@nhs.net; Stephanie Sudikoff, MD, Yale-New Haven Health, Stephanie.sudikoff@ynhh.org; Ilana Bank, MD, Montreal Children's Hospital, ilana.bank@mcgill.ca; Ronald Gottesman, MD, Montreal Children's Hospital, ronald.gottesman@mcgill.ca; Mark Adler, MD, Ann \& Robert H Lurie Children's Hospital of 
Chicago, m-adler@northwestern.edu; Alex Charnovich, MD, Johns Hopkins University School of Medicine, echarno1@jhmi.edu; Kimberly Marohn, MD, Baystate Children's Hospital, Kimberly. marohnmd@bhs.org; Nicola Robertson, BSc, Alberta Children's Hospital, nicola.robertson@albertahealthservices.ca; Jordan DuvalArnould, MPH, CPH, DrPH[c], Johns Hopkins University School of Medicine, jordan@jhu.edu; Nnenna Chime, MD, MPH, Albert Einstein College of Medicine and Children's Hospital at Montefiore, nchime1@jhmi.edu. Additional Contributors: The authors would like to acknowledge the contributions of the following individuals, who assisted with data collection and recruitment: Traci Robinson, RN; Elaine Gilfoyle, MD, MEd; Deanna Koot, RN, MN; Wendy Bissett, RN; Helen Catena, RN; Kevin Murray, KidSIM-ASPIRE Simulation Research Program, Alberta Children's Hospital; Amber Q. Youngblood, BSN, RN; J. Lynn Zinkan, RN, MPH, Children's of Alabama; Keven Cabrera, Columbia University College of Physicians and Surgeons; Max G. Dannecker, NREMT-I/85, Lifespan Medical Simulation Center; Laura McKenzie, RN, Stollery Children's Hospital; Jean Francois Trudel, RRT, Montreal Children's Hospital; Linda Crelinsten, RN, MA, The Arnold and Blema Steinberg McGill Medical Simulation Centre; Laura Clifford, BSc, Alice Parham, Caroline Box, RGN, RSCN, BSC (hons); Paul Sampson, BSc, MBChB; Tom Jerrom, Darshana Bhattacharjee, Annie Noble, RN, BSc, Cert Ed. FHEA; Rob Kozlowski, BSc Hons; Sarah Sibley, Bristol Royal Hospital for Children; Bonnie Mobley, BSN, Ann \& Robert H. Lurie Children's Hospital of Chicago; Michele Trinka, MSN, RN, CCRN, PCCN; Dayna Downing, MBA; Roxana Ploski, BS; Kay Martin, BSRC, RRT-NPS; Gail Dutcher, RRT-NPS, AE-C; Michael Williams, BSN, RN; Marcus Brown, BS, NREMT, Children's Medical Center of Dallas. No compensation was received by those cited previously for their contributions to the study.

Financial support: This study was funded by a research grant from the Heart and Stroke Foundation of Canada and the Canadian Institutes of Health Research (OMF-110354). Funds from this grant were used for the design and conduct of the study, data collection, data management, and data analysis. The INSPIRE network receives infrastructure funding from the Laerdal Foundation for Acute Medicine. Funds from this grant were used to support the INSPIRE network administrative coordinator who supported this project. Laerdal Corporation loaned each recruitment site a SimJunior manikin for use in the study and donated CPRCards for the study. No financial compensation or grant funding was received from Laerdal Corporation for conducting this research.

Competing interests: None declared.

\section{REFERENCES}

1. Meaney PA, Bobrow BJ, Mancini ME, et al. Cardiopulmonary resuscitation quality: improving cardiac resuscitation outcomes both inside and outside the hospital. A consensus statement from the American Heart Association. Circulation 2013;128:417-35.
2. Cheskes S, Schmicker RH, Christenson J, et al. Perishock pause: an independent predictor of survival from out-ofhospital shockable cardiac arrest. Circulation 2011;124:58-66.

3. Christenson J, Andrusiek D, Everson-Stewart S, et al. Chest compression fraction determines survival in patients with out-of-hospital ventricular fibrillation. Circulation 2009; 120:1241-7.

4. Stiell IG, Brown SP, Christenson J, et al. What is the role of chest compression depth during out-of-hospital cardiac arrest resuscitation? Crit Care Med 2012;40:1192-8.

5. Idris AH, Guffey D, Aufderheide TP, et al. Relationship between chest compression rates and outcomes from cardiac arrest. Circulation 2012;125:3004-12.

6. Wik L, Steen PA, Bircher NG. Quality of bystander cardiopulmonary resuscitation influences outcome after prehospital cardiac arrest. Resuscitation 1994;28:195-203.

7. Sutton RM, Wolfe H, Nishisaki A, et al. Pushing harder, pushing faster, minimizing interruptions... But falling short of 2010 cardiopulmonary resuscitation targets during inhospital pediatric and adolescent resuscitation. Resuscitation 2013;84:1680-4.

8. Abella B, Alvarado JP, Myklebust H, et al. Quality of cardiopulmonary resuscitation during in-hospital cardiac arrest. JAMA 2005;293:305-10.

9. Wik L, Kramer-Johansen J, Myklebust H, et al. Quality of cardiopulmonary resuscitation during out-of-hospital cardiac arrest. FAMA 2005;293:299-304.

10. Sutton R, Niles D, Nysaether J, et al. Quantitative analysis of CPR quality during in-hospital resuscitation of older children and adolescents. Pediatrics 2009;124:1930-8.

11. Sutton R, Maltese M, Niles D, et al. Quantitative analysis of chest compression interruption during in-hospital resuscitation of older children and adolescents. Resuscitation 2009;80:1259-63.

12. Sutton RM, Niles D, French B, et al. First quantitative analysis of cardiopulmonary resuscitation quality during in-hospital cardiac arrests of young children. Resuscitation 2014;85:70-4.

13. Sutton RM, Niles D, Meaney PA, et al. "Booster" training: evaluation of instructor-led bedside cardiopulmonary resuscitation skill training and automated corrective feedback to improve cardiopulmonary resuscitation compliance of pediatric basic life support providers during simulated cardiac arrest. Pediatr Crit Care Med 2011;12: e116-21.

14. Sutton RM, Niles D, Meaney PA, et al. Low-dose, high-frequency CPR training improves skill retention of in-hospital pediatric providers. Pediatrics 2011;128:e145-51.

15. Cheng A, Brown L, Duff J, et al.; for the INSPIRE CPR Investigators. Improving cardiopulmonary resuscitation with a CPR feedback device and refresher simulations (CPR CARES Study): a multicenter, randomized trial. $7 A M A$ Pediatr 2015;169(2):1-9.

16. Cheng A, Hunt EA, Grant D, et al. Variability in quality of chest compressions provided during simulated cardiac arrest across nine pediatric institutions. Resuscitation 2015; 97:13-9.

17. Cheng A, Overly F, Kessler D, et al. Perception of CPR quality: influence of CPR feedback, just-in-time training and provider role. Resuscitation 2015;87:44-50. 
18. McNulty T, Gallagher P, Rice BJ, et al. AS24 The relationship between healthcare staff height and the ability to perform effective chest compressions in adults. Resuscitation 2011;82(Supp 1):S7.

19. Ebbeling LG, Esposito EC, Fried DA, et al. Abstract 245: Increasing rescuer height is associated with higher frequency of leaning during chest compressions. Circulation 2010;122:A245.

20. Lee DH, Kim CW, Kim SE, et al. Use of step stool during resuscitation improved the quality of chest compression in simulated resuscitation. Emerg Med Australas 2012;24:369-73.

21. Edelson DP, Call SL, Tuen TC, et al. The impact of a step stool on cardiopulmonary resuscitation: a cross-over mannequin study. Resuscitation 2012;83:874-8.

22. Niles D, Donoghue A, Kalsi MS, et al. "Rolling Refreshers": a novel approach to maintain CPR psychomotor skill competence. Resuscitation 2009;80:909-12.

23. Yeung J, Meeks R, Edelson D, et al. The use of CPR feedback/prompt devices during training and CPR performance: a systematic review. Resuscitation 2009;80:743-51.

24. Kirkbright S, Finn J, Tohira H, et al. Audiovisual feedback device use by health care professionals during CPR: a systematic review and meta-analysis of randomized and non-randomised trials. Resuscitation 2014;85:460-71.

25. Bhanji F, Donoghue A, Wolff M, et al. Part 14: Education. 2015 American Heart Association Guidelines Update for
Cardiopulmonary Resuscitation and Emergency Cardiovascular Care. Circulation 2015;132:S561-73.

26. Cheng A, Auerbach M, Chang T, et al. Designing and conducting simulation-based research. Pediatrics 2014; 133(6):1091-101.

27. Nishisaki A, Nysaether J, Maltese M, et al. Effect of mattress deflection on CPR quality assessment for older children and adolescents. Resuscitation 2009;80:540-5.

28. Wikipedia. Average height around the world. Available at: https://en.wikipedia.org/wiki/Template:Average_height_ around_the_world (accessed 1 July 2015).

29. Sutton RM, French B, Niles DE, et al. 2010. American Heart Association recommended compression depth during pediatric in-hospital resuscitations are associated with survival. Resuscitation 2014;85:1179-84.

30. Vadeboncoeur T, Stolz U, Panchal A, et al. Chest compression depth and survival in out-of-hospital cardiac arrest. Resuscitation 2014;85:182-8.

31. Edelson DP, Abella BS, Kramer-Johansen J, et al. Effects of compression depth and pre-shock pauses predict defibrillation failure during cardiac arrest. Resuscitation 2006;71: 137-45.

32. Kramer-Johansen J, Myklebust H, Wik L, et al. Quality of out-of-hospital cardiopulmonary resuscitation with real time automated feedback: a prospective interventional study. Resuscitation 2006;71:283-92. 